University of Nebraska - Lincoln

DigitalCommons@University of Nebraska - Lincoln

Robert G. Fuller Publications and Presentations Research Papers in Physics and Astronomy

April 1993

\title{
Millikan Lecture 1992: Hypermedia and the knowing of physics: Standing upon the shoulders of giants
}

Robert Fuller

rfuller@neb.rr.com

Follow this and additional works at: https://digitalcommons.unl.edu/physicsfuller

Part of the Physics Commons

Fuller, Robert, "Millikan Lecture 1992: Hypermedia and the knowing of physics: Standing upon the shoulders of giants" (1993). Robert G. Fuller Publications and Presentations. 10.

https://digitalcommons.unl.edu/physicsfuller/10

This Article is brought to you for free and open access by the Research Papers in Physics and Astronomy at DigitalCommons@University of Nebraska - Lincoln. It has been accepted for inclusion in Robert G. Fuller Publications and Presentations by an authorized administrator of DigitalCommons@University of Nebraska - Lincoln. 


\title{
Millikan Lecture 1992: Hypermedia and the knowing of physics: Standing upon the shoulders of giants
}

\author{
Robert G. Fuller \\ Department of Physics and Astronomy, University of Nebraska-Lincoln, Lincoln, Nebraska 68588-0109
}

Hypermedia is defined and its roots briefly discussed. Models of knowing physics and of intrinsically motivating instruction are presented. Uses of hypermedia to increase the knowing of physics and the motivation of learners are proposed.

\section{INTRODUCTION}

As we think together about hypermedia and the knowing of physics, it seems clear to me that the first uses of hypermedia will be in classroom settings. So I want to focus our attention first upon the classroom.

Recall a memorable learning experience you have had in a classroom. You may find it helpful to write down a brief description of that experience to help you consider a variety of the aspects of that learning experience. It may have been an experience you had as a student, or as a teacher, or as a classroom observer. As you reflect upon that classroom learning experience, what was it that made it memorable? Try to answer some additional questions about that memorable classroom experience, such as: What did you learn? Where was it? When was it? Who taught you? What was the learning process you used?

I have made an informal survey looking for common aspects of the memorable learning experiences that people have had. It has not been a "scientific" survey, but many people have shared with me their personal classroom learning experience.

What are the common threads of our memorable classroom learning experiences?

I have come to believe that a key element in a memorable classroom experience for most people is what I call the "Ah-Ha" experience. Time and time again people tell me of an experience in a classroom setting when some concept suddenly clicked for them. It may have been the sudden recognition of the power of vector notation, or the insight that all of statics is contained in just a few equations that sum forces and torques and set them equal to zero.

For some people the actual classroom experience sets up an "Ah-Ha" that happens later, but the " $\mathrm{Ah}-\mathrm{Ha}$ " aspect of the experience is nearly always present.

If hypermedia, then, is to help us become more effective in teaching physics, then we must bend the power of hypermedia toward providing classroom learners with more "Ah-Ha" experiences. This is the issue to which I want to turn our attention. How can hypermedia be used to enhance the knowing of physics?

\section{WHAT IS HYPERMEDIA?}

Hypermedia has a long history. Vannevar Bush, Director, U.S. Office of Scientific Research and Development published an article, "As We May Think" in the Atlantic

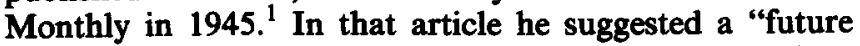
device for individual use, which is a sort of mechanized private file and library." Remember, that this was before the discovery of the transistor! The existing computers used vacuum tubes and punch cards, or paper tape. Nev- ertheless, Mr. Bush conceived of many of the features that are now common attributes of personal computers. He suggested: scanning input as well as keyboard input, mass storage, display screens, rapid browsing, personal links with retrieval trails, and the purchase of published documents for this device. While Bush thought of them as film strips and mechanical devices, we know them as common features of the software and hardware of today's personal computers.

Nearly 20 years later, in 1962, Douglas C. Engelbart, working at the Stanford Research Institute, began to develop a system for augmenting human intellect. ${ }^{2}$ This system was designed to increase the capability of humans to: approach a complex problem, gain suitable comprehension, and derive solutions to problems. Engelbart and his co-workers developed a number of the features of computer systems that we now take for granted. His group invented the computer mouse as an input device, implemented electronic mail, and devised a system of links and nodes for text documents.

The term "hypertext" was coined by Theodor H. Nelson in 1965 for nonlinear, or non-sequential, writing and reading. ${ }^{3} \mathrm{He}$ envisioned a multidimensional text with junctions for burrowing into the material for details, definitions, and background information. Hypermedia is the extension of hypertext to include graphics, video, animation, and sound.

So far we have not seen very much use of hypermedia in classrooms. Hypermedia is an important topic of discussion at computer and corporate training conferences., $\mathrm{A}$ system that could make use of hypermedia in a physics classroom is readily available today (see Fig. 1). Such a system uses a personal computer as the basic ingredient. To the computer are added digital video, a compact disc read-only memory [CD-ROM] drive, and the laboratory interface hardware and software to make measurements. Today such a system costs about $\$ 5000$. If the changes in computers and software continue for a few years at the present rate, by the time this year's freshmen graduate a complete hypermedia system will cost about $\$ 1000$.

The essential question for us to try to answer as physics educators is not whether hypermedia is a real phenomenon or not. The market forces in the commercial sector of the industrialized countries and their needs for more employee training will drive the development of hypermedia. The essential question for us is: How do we use hypermedia to improve the knowing of physics?

\section{WHAT DOES IT MEAN TO KNOW PHYSICS?}

My understanding of this question has been largely shaped by my experiences at American Association of 
Today's Hypermedia Workstation for Physics Instruction

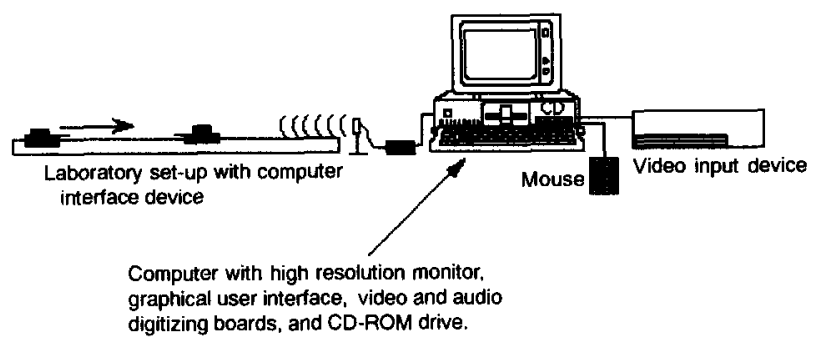

Fig. 1. Today's hypermedia workstation includes a high-speed personal computer with a high-resolution graphics monitor. The computer uses graphical user interface software to display text and graphics on the screen. The computer includes video and audio digitizing boards as well as a compact disc read only memory (CD-ROM) drive. A typical hypermedia system is completed by video and audio input devices. Such a system for use in physics also includes a laboratory interface device and transducers. Now such systems are composed of components from several different manufacturers and costs about $\$ 5000$. It is projected to be available as a single unit from one manufacturer for about $\$ 1000$ in 4 years.

Physics Teachers (AAPT) meetings. When I attended my first summer AAPT meeting in 1971, I had just finished teaching a large lecture section of general physics for premedical students and I was disappointed by their average exam scores of $50 \%$. I heard a paper on the Keller Plan (or Personalized System of Instruction, PSI) about which I knew nothing, and from the paper I could only figure out a little bit. When I returned home from the meeting I found the July issue of the American Journal of Physics awaiting me. In that issue I read the article on "Physics Teaching by the Keller Plan at MIT" by Ben Green. ${ }^{6}$ It changed my career forever! I immediately recognized in the Keller Plan an answer to my question about student performance. I began to change my course into a Keller Plan format and taught my first Keller Plan physics course in the fall of 1971. After attending a conference on the Keller Plan at MIT in the fall of 1971, I recognized the need for a nonlecture way to share information about the Keller Plan and produced a film on the Keller Plan for the University of Nebraska-Lincoln (UNL) Media Center "Personalized System of Instruction, An Alternative".? That film was the largest circulating film in the UNL Media Center for a few years with as many as $\mathbf{2 5}$ copies rented out continuously. The Keller Plan is based on the assumption that learning is an individual matter. It is mastery oriented, student tutored, and self-paced. It has been classroom tested and shown effective for classes of all sizes and at low cost. It has been adapted to many disciplines with success.

In the fall of 1971, then, I committed myself to the teaching of physics using the Keller Plan. In the spring of 1972, while teaching the pre-med students physics using the Keller Plan, I was accosted one day by a student who had just failed in his second attempt to pass a mastery test. He said, "You cheated me. The second test was nothing like the first test." and stormed out of the classroom. I was stunned. I had spent many hours writing mastery tests and trying to make each version of the test as equivalent to the others as possible. What did this student mean?

Here I discovered what I only could name a year later. The "Ah-Ha" experiences that make classroom learning experiences memorable are nearly always preceded by experiences that are puzzlements to our minds.

Almost a year later, I was sitting in a ballroom at an AAPT/APS meeting in New York City listening to an invited paper being given by Dr. John Renner. He was proceeding to describe how the world looks to a student who is using concrete reasoning. Click! Ah-Ha! Suddenly, I recalled the student from nearly a year before and his question fell into a new framework, the concept of cognitive development as formulated by Jean Piaget and interpreted by Robert Karplus. Once again, when I returned home I discovered an article in the American Journal of Physics that laid out in some detail the thoughts of Renner. ${ }^{8}$ Later that year I joined Karplus and a few others in preparing a workshop for AAPT members on these ideas. That workshop "Physics Teaching and the Development of Reasoning," was offered for several years at AAPT meetings and was packaged and distributed for use at AAPT section meetings. Karplus summarized many of the ideas of the workshop in a review article that was published in 1977. ${ }^{9}$ His own film "Formal Reasoning Patterns," serves as an excellent, visual introduction to his work and his intent to have learning experiences be student centered. ${ }^{10}$

Meanwhile, at the University of Nebraska-Lincoln I helped develop a multidisciplinary, Piagetian-based program for college freshmen. This program called the ADAPT program, has continued to be the core of my teaching and learning philosophy ever since. Now many features of this philosophy have become widely known as the constructivist view of knowing. ${ }^{11}$

In this view, people gradually change their patterns of reasoning and advance from one level of understanding to another. The change is one in which a person actively searches for relationships and patterns to resolve contradictions and to bring coherence to a new set of experiences. This is a life-long process of change. It occurs when what we think we know about nature is not substantiated by our experiences, that somehow nature does not make sense. A driving force in the constructivist understanding of "knowing" is the importance of contradiction and our innate desire to want to understand ourselves and our environment. Hence, the primary task of hypermedia in the knowing of physics is to facilitate these on-going changes in the mental processes of students as these processes are related to concepts in physics. What we need to do with hypermedia is not make physics easy, but to make it slightly complicated. Thus the hypermedia task is to provide a credible reality and a challenge to existing mental processes of the students, in short, to provoke them into an appropriate level of cognitive conflict.

In addition to letting our approach to the knowing of physics be a constructive mental process, we must somehow make it intrinsically motivating. In considering this aspect of knowing physics I rely very heavily upon the work of Thomas Malone. ${ }^{12}$ In his work Malone identified three aspects of a learning experience that can make it intrinsically motivating. He labeled those three aspects as fantasy, challenge, and curiosity.

\section{A. Fantasy}

An important aspect of learning is the theme, or story line. Physicists already use fantasy, e.g., point particles, frictionless planes. But our fantasies are seen as boring by many of our students. 
As an example of using a storyline to motivate students to learn physics, consider the historical narrative we wrote for our Tacoma Narrows Bridge videodisc. ${ }^{13}$ A portion of the video is accompanied by the first person narration of the newspaper reporter who drove his automobile onto the bridge in 1940 .

"I saw the Tacoma Narrows Bridge die! And only by the grace of God escaped dying with it."

"I have been near death many times in my life, but not even in my worst experiences in France did I know the feeling of helpless horror that gripped me when I was trapped on the bridge this morning...."

"Those who stood on the shore and watched the bridge in its death agony can have no conception of the violence of movement felt by one out beyond the towers. Safely back at the toll plaza, I saw the bridge in its final collapse and saw my car plunge into the Narrows. With real tragedy, disaster and blasted dreams all around me, I believe that right at this minute what appalls me most is that within a few hours I must tell my daughter that her dog is dead when I might have saved him."

I believe that storyline has the kind of fantasy and emotion that many of the students in our physics courses find appealing. They begin to believe that physics has, in fact, some relationship to these kinds of everyday events. From my point of view, I cannot emphasize enough that we, as a community of physics educators, have not been very creative in developing physics stories to engage and motivate students.

Fantasy makes instructional environments more interesting and more educational. A good fantasy can help learners apply old knowledge to new situations and by provoking vivid images a good fantasy can help learners remember better. We are fortunate in physics. We have a wide variety of visual images from which to select that can be interesting to our students. Consider the high speed film clip of the cat drop shown on the "Physics Vignettes" videodisc. ${ }^{14}$ How does a cat manage to turn over and land on its feet? How could a person, suspended right side up over a swimming pool, drop and rotate to go into the pool head first?

I submit that this kind of visual imagery, discussion about these kinds of observations, and an opportunity to take students to a swimming pool and drop them in it, will provide student interest in physics that we usually do not get. In addition, hypermedia can also enable us to offer physics stories where different students can choose, or be offered, different fantasies.

\section{B. Challenge}

Intrinsically motivating instruction challenges the learners. A challenging environment provides goals whose attainment is uncertain. A good goal is personally meaningful for the learners to achieve. Such goals use the skills that the learners are being taught. Frequently such a goal is part of a fantasy that we construct for the learners. The good goal allows the learners to have a sense of power, once they have accomplished it, that they can do more. Its attainment enables the learners to perform new tasks. Hypermedia, I argue, provides us with some wonderful new ap- proaches to this aspect of intrinsically motivating instruction. Hypermedia enables us to provide goals with variable difficulty, randomness and multiple levels.

We can use hypermedia to hide information. Almost no one who writes about computer-based instruction writes about the power of the computer to hide things. You cannot hide anything in a book. We are safe because the students do not read them. But the answers to the questions are in there if they look. You can fix a hypermedia program so that it will not show students the information they need if they do not know enough to ask for it. Isn't it partly the hiddeness of nature that got us hooked on physics? Now we can provide an opportunity for that same kind of surprise and "Ah-Ha" for our physics students through the proper use of hypermedia.

An appropriate challenge is captivating because it engages a learner's self-esteem. It is very important for us to understand that our students should have higher selfesteem at the end of our physics courses than at the beginning. Too often I hear stories about physics learning experiences, from introductory level through graduate oral exams, that tell about how depressed the students are at the end. This is not an appropriate function of our task as educators. Our students should be empowered and have a positive self-esteem when they finish our physics courses. One of the ways to accomplish that is to challenge our students to use physics to think about everyday events, show gymnastics events, as illustrated on the "Studies in Motion" videodisc, and discuss the applications of physics to them. ${ }^{15}$ For example, show such events as an aerial walkover or a power lift. Step through each event a single frame at a time, seeing it every 30th of a second, and discuss the location of the center of mass of the gymnast in each frame.

\section{Curiosity}

Human beings are naturally curious. A learning task needs to provide an optimal level of informational complexity for us, as learners, to be attracted to it. If a task is too simple we are not interested. It should be surprising and novel, but not completely incomprehensible. Human beings are made curious by both sensory stimuli and cognitive stimuli. Hypermedia with images and sound allows us to provide both of these. For example, ask your students to consider what happens to a cyclist who discovers a car door is suddenly opened in front of her as illustrated in the chapter on braking on the "Energy Transformations Featuring the Bicycle" videodisc. ${ }^{16}$

Hypermedia needs to present just enough information to make learners' existing knowledge seem to be incomplete, inconsistent, or unparsimonious. Then natural human curiosity helps to motivate them to learn more.

Perhaps the best application of the ideas of Karplus and Malone that I have done was a project I did with David Winch. In 1988 Dave and I developed a HyperCard stack which won a national SuperStacks contest for the best use of HyperCard in a higher education. We tried to set the concept of momentum conservation in a story. It is called "Guilty or Innocent?"17 This physics activity invites the student to become a technical expert in a court case involving an automobile collision. The student can interview witnesses and collect data from an amateur videotape of the event. Then the student must go to court and appear as a technical witness to answer questions asked by a lawyer. 
The lesson makes use of the flexibility of HyperCard to offer the student animation, narration, and many options for investigating the "accident." I use this as a homework assignment for my students, "Write an Accident Report."

Another use of hypermedia that can be important for us in physics will include the compact disc read only memory, CD-ROM. With this technology we will have access to large specialized collections of information, text as well as graphics, sound as well as video images. A CD-ROM will be able to provide us and students, at our desks and our lab stations, huge amounts of physics information.

We are presently preparing a special physics CD-ROM called the "Physics InfoMall." 18 We estimate this CDROM will be able to offer about 50000 pages of physics textual information (equivalent to about 50 books) including line drawings and graphs. The CD-ROM will include search and retrieval software that will enable us to find and sort information. We will be able to cut, paste and insert text and graphics from one source to another and create our own new document from information from a variety of sources. We are just beginning this process and had a first version for field testing in the fall of 1992. The "Physics InfoMall" will eventually include: reference data (equivalent to about 10 books) such as physical constants, mathematical functions, periodic table, and data on elements and compounds; biographical data (equivalent to about 3 books) about famous physicists; membership directories of professional organizations; publishers and equipment supply house catalogs; text books (equivalent to about 27 books) of physics, from eighth grade level through graduate school; and valued physics articles (equivalent to about 10 books) such as tutorials, review articles, Richtmyer and Millikan lectures, resource letters and abstracts.

In conclusion, I believe that hypermedia will be able to help us improve physics teaching if we use it to: encourage active learning techniques, develop reciprocity and cooperation among students, give prompt and appropriate feedback, emphasize time on task, communicate high expectations and enhance student self-esteem, respect diverse talents and ways of learning, and encourage contacts between students and teachers.

Furthermore, I believe that working together we can stand upon the shoulders of the giants. We can build upon the hypermedia ideas of Vannevar Bush, Douglas Engelbart and Theodor Nelson to enable our students to know the physics concepts illuminated by Issac Newton, James Maxwell, Albert Einstein, and others. We can inform our teaching by the insights of Robert Karplus and Jean Piaget and by the theory of intrinsically motivating instruction described by Thomas Malone.

Together, using the power of hypermedia, we can make an impossible dream come true... Every student in every physics course will complete the course with heightened interest in the natural world and increased self-esteem.

\section{ACKNOWLEDGMENTS}

On the path that led me from a beginning physics faculty member to a recipient of the 1992 Milikan medal, I have worked with about 200 different professional colleagues, from Ahlschwede, Margrethe to Zollman, Dean on more than 35 different educational projects, from the ADAPT program for UNL freshmen to "Wondering About Physics...Using Spreadsheets to Find Out."19 What I now think I know I learned mostly from them. Thanks.
${ }^{1} V$. Bush, "As We May Think," Atlantic Monthly 176, 101-108 (1945). ${ }^{2}$ D. C. Engelbart, "A conceptual framework for the augmentation of man's intellect," in Vistas in Information Handling, Vol. 1, edited by $P$. D. Howerton and D. C. Weeks (Spartan Books, Washington; D.C., 1963), pp. 1-29.

${ }^{3}$ T. H. Nelson, "Dream machines: New freedoms through computer screens-A minority report," in Computer Lib: You Can and Must Understand Computers Now (Hugo's Book Service, Chicago, IL, 1974).

${ }^{4}$ S. Ambron and K. Hooper, (editors) Interactive Multimedia, Visions of Multimedia for Developers, Educators and Information Providers (Microsoft Press, Redmond, WA, 1988).

${ }^{5}$ R. E. Hom, Mapping Hypertext (Lexington Institute, Lexington, MA, 1989).

${ }^{6}$ B. A. Green, Jr., "Physics teaching by the Keller plan at MIT," Am. J. Phys. 39, 764-775 (1971).

7"Personalized system of instruction: An alternative" University of Nebraska-Lincoln Media Center, 1972, 12 min., b\&w 16-mm film.

${ }^{8} \mathrm{~J}$. W. McKinnon and J. W. Renner, "Are colleges interested in intellectual development?," Am. J. Phys. 39, 1047-1052 (1971).

${ }^{9} R$. Karplus, "Science teaching and the development of reasoning," J. Res. Sci. Teach. 14, 169-175 (1977).

${ }^{10}$ R. Karplus and R. Peterson, "Formal Reasoning Patterns," Davidson Films, Davis, CA, 1976.

${ }^{11}$ R. E. Yager, "The constructivist learning model," Sci. Teach. 58, 52-57 (1991).

${ }^{12}$ T. Malone, "Toward a theory of intrinsically motivating instruction," Cognitive Sci. 4, 333-369 (1981).

${ }^{13}$ R. G. Fuller, D. A. Zollman, and T. C. Campbell, "The Puzzle of the Tacoma Narrows Bridge Collapse" (a videodisc) (Wiley, New York, 1982).

${ }^{14}$ R. G. Fuller and D. I. Dykstra, Jr., "Physics Vignettes" (a videodisc) (Willey, New York, 1989), Chap. 4.

${ }^{15}$ R. G. Fuller and D. A. Zollman, "Studies in Motion" (a videodisc), University of Nebraska-Lincoln, 1983.

${ }^{16}$ D. A. Zollman and R. G. Fuller, "Energy Transformations Featuring The Bicycle" (a videodisc), University of Nebraska_Lincoln, 1984.

${ }^{17}$ R. G. Fuller, D. Winch, K. Armstrong, and A. S. Fuller, "Guilty or Innocent?" (a HyperCard stack), 1988. Now available as a software product from the American Association of Physics Teachers.

${ }^{18}$ R. G. Fuller and D. A. Zollman, "Every Physics Teacher's CD-ROM Toolkit," a project supported by the National Science Foundation, MDR \#9054923. Call 800-232-0133, ext 7167 for additional information.

${ }^{19}$ I am grateful for the help and assistance provided on various projects by the following people: parents (1935-date) Harold Q Fuller and Charlotte Mae Fuller (deceased 1985); wife and children (1961-date) Margaret A. Sanders Fuller, Amy E. Fuller, Laurie S. Fuller, and Andrew S. Fuller; physics film making (1970) Marvin Hass; Cooperative College School Science Programs grades K-6 (1971-73) Ward Sims, Darlene Rischling; Film Loop Instructional Course (FLIC) in physics (1972) Dennis Albers, and 24 participants including: Dean Zollman, Tom Campbell, Tom Greenslade, Tom Rossing, John Dowling, et al.; Physics Teaching and the Development of Reasoning Workshop (1973-1979) Jean Piaget, Robert Karplus, John Renner, Frank Collea, Les Paldy, Arnold Strassenberg; Physics Including Human Applications (1973-78), Harold Q Fuller, Richard M. Fuller, Tom Campbell; Quantitative Reasoning and Science Teaching in Nebraska, grades K-6 (1974-75) Walter Mientka, James Fejfar, Donna West, Ward Sims; Multidiscipinary Piagetian-based Program for College Freshmen (ADAPT) (1974-today) Mel Thornton, Bud Narveson, Stella Moline, Marilyn McDowell, Vernon Williams, Carol Tomlinson-Keasey, Bob Bergstrom, James McShane, Joy Ritchie, Charles Mignon, Les Duly, Martin Peterson, Ellen Dubas, Margarethe Ahlschwede, Dani Weinberg, Glenn Sowell, Tom Campbell, Scott Stevens, Betty Windham, Robert Karplus; Calculus-based Physics Modules for Keller Plan courses (1975-78) Tom Campbell, Harold Q Fuller, Al Bartlett, Kate McCaffrey, Carol Robel, Stella Moline, and 15 authors including Robert Karplus, David Winch, David Joseph et al.; Physical Science Modules for Bioscience Students (1975-79) Tom Campbell Allen Killpatrick, Norman Chonacky, Andrew Marino, Stella Moline, and a national steering committee including Russell Hobbie et al; Program for the Advancement of the College Teaching of Science (PACTS) (1978-81) Dave Brooks, Stella Moline, project participants such as Helen James, Cliff Lewis, Bob Silberman; Local Course Improvement 
(LOCI) project (1973-80) Dave Brooks, Sam Treves, Laird Thompson, Ed Schmidt, Ed Zimmerman; Comprehensive Approach to Undergraduate Science Education (CAUSE) (1979-82) Dave Brooks, Cliff Bettis; The Puzzle of the Tacoma Narrows Bridge Collapse videodisc (1979-82) Dean Zollman, Tom Campbell, NETV Videodisc Design/Production Group, Barney Elliott, Dorothy Derringer, Gary Carlson, Tom Tipton; Junior high Skylab physical science project (1979-81) Tom Campbell, Dean Zollman; Centennial Education program (1979-81) Annetta Young, Marilyn McDowell, Jerry Petr, Elizabeth Carpenter, Frances Kaye, Dani Weinberg, Don Cunningham, Patrice Berger, Luiz Perdomo, Terri Nygren, Jim Michel, Bob Bergstrom, Patrick Hill, Arnie Strassenberg; Control Data Corporation Physics lessons (1980-82) Pat Ridgely, Carl Tomizuka, Ed Gibson, Richard Herr; University of Nebraska Computer-based Learning Experiment (UNCLE) (1982-83) Clifford Bettis, Dave Winch, Paul Menter, Bruce Oberg; Annenberg/ $C P B$ Videodisc project two physics videodiscs (1982-84) Dean Zollman, Jack McBride NETV Videodisc Design/Production Group, Dave Brooks, William Leonard, Tom Tipton; Developing Student Confidence in Physics Workshop for AAPT (1982-85) Gary Allen, Dean Zollman, Damian Nichols, Arnold Strassenberg, Judy Aubrecht, Jeffrey Mallow, Susan Agruso, Carol-ann Tripp; British Open University- "Teddy Bear" videodisc (1982-83) David Blackburn, Tony Bates, Diane Laurillard, Keith Williams, Paul Blenkhorn, Martin Wright; Tandy computers in physics curriculum project (1986-88) Ed Jones, Cliff Bettis, Bob Hardy; Physics Deminstration/Laboratory Institutes for High School Teachers (1986-88) Charles R. Lang and Westside High School staff, Bob Klein, Pete Adwers, John Rogers, Doug Wilson, Jack Skrocky, Cliff Bettis, almost 100 high school physics teacher participants including Deb Beightol and Jan Greiner; Skylab Physics videodisc (1986-87) Rick Swanson, Sgt. Horne, DFSIV, Dean Zollman; Science of Flight videodisc (1987-88) Rick Swanson, Sgt. Horne, Keith Williams, George Hept; Wondering About Physics... Using Spreadsheets to Find Out, What If? and Physics Vignettes (1986-88) Dewey Dyk- stra, John Wiley and Sons, Inc.; Guilty or Innocent? Superstack award winning HyperCard lesson (1988) Dave Winch, Karl Armstrong, Andrew Fuller; Physics: Cinema Classics project (1989-92) Chuck Lang, Dean Zollman, Carol-ann Tripp, Dave Winch, NETV Videodisc Design/Production Group, Marilyn McDowell, Allen Specht, Brenda West, Michelle Mason, John Dowling, Donna Willis, AAPT; New Careers in Science for Rural Girls in Nebraska \& Young Scholars Institutes (1989-1991) Nan Lindsley-Griffin, Jan Wright; Bridges, Bicycles and Traffic-Thematic Physical Science Lessons (1989-date) Dean Zollman, Charles Lang, Carol-ann Tripp, Ton Ellermeijer, several other physicists and physics teachers in The Netherlands, Leendert Kersten; Tranforming Physics Content Using New Technologies USAFA (1990-92) Dean Zollman, Dave Winch, Glenn Sowell, Rolf Enger, James Head, Marilyn McDowell, Margaret Fuller, and 35 participants, including Marvin De Jong, Gregor Novak, and Doyle Davis; Physics Teacher's CD-ROM Toolkit project (1991-date) Dean Zollman, Evelyn Tuska Patterson, Jan Tunison, Michelle Mason, Laurie Gottsche, Chuck Lang, Courtney Willis, Debra Beightol, Carol-ann Tripp, Jan Greiner, Tim Ingoldsby, Rolf Enger, Jacqueline Spears, Marilyn McDowell, Gerhardt Salinger, UNL, and KSU Student Helpers; New Technologies to Improve Physics Laboratories project (1991-date) Gregor Novak, Doyle Davis, Linda McDonald, Larry Martin, Evelyn Tuska Patterson; Using New Technologies to Teach Physics USAFA (1991-date) Evelyn Tuska Patterson, Glenn Sowell, Dave Winch, Marvin De Jong, James Head, Rolf Enger, Marilyn McDowell, Margaret Fuller, and 39 participants; Creating CD-ROMs for Science Education Conference (1992) Marilyn McDowell, Jan Tunison, Harmon Tunison, Michelle Mason, Evelyn Tuska Patterson, and conference participants including Mary Budd Rowe, Gregory Rawlings, Gerhardt Salinger, Kathy Fuller, Mary Miller, and Dave Brooks; Improving physics laboratories for bioscience students (1992-date) Evelyn Tuska Patterson, Doug Zbylut, Jack Morris, and Eric Davies.

\title{
A magnetic suspension system for atoms and bar magnets
}

\author{
C. Sackett, E. Cornell, C. Monroe, and C. Wieman \\ Joint Institute for Laboratory Astrophysics and the Department of Physics, University of Colorado, \\ Boulder, Colorado 80309-0440
}

(Received 21 January 1992; accepted 20 September 1992)

\begin{abstract}
A three dimensional magnetic confinement system is presented which will trap both macroscopic and atomic magnetic dipoles. The dipole is confined by dc and oscillating magnetic fields, and its motion is described by the Mathieu equation. Most aspects of the dynamics of the trapped objects depend only on the ratio of the magnetic moment to the mass of the dipole. Similar motion was observed for masses varying over 21 orders of magnitude (from 1 atom to $0.2 \mathrm{~g}$ ). The trap is constructed from inexpensive permanent magnets and small coils which are driven by $60 \mathrm{~Hz}$ line current. The design of the trap as well as the behavior of the trapped particle are discussed herein.
\end{abstract}

\section{INTRODUCTION}

People have always been fascinated by the sight of an object suspended in space, free from contact with any material substance. Demonstrations of such an event are often the centerpiece of magic shows, NASA public relations, and presentations on high temperature superconductivity. Recently, atomic physicists have developed a particular interest in these phenomena. Their work would probably make an excellent magic trick for a stage act, but is of course well grounded in physical theory. Electric or magnetic fields, produced by some relatively distant source, are used to suspend and confine isolated ions, electrons, and atoms. When confined in this manner, the particles are free from the usual perturbations produced by nearby atoms, and thus can be studied with unprecedented precision. The Nobel prize in physics was awarded to Dehmelt and Paul for their pioneering work in the field of ion trapping. While trapping of charged particles is a mature field, the trapping of neutral particles using magnetic fields is more difficult 